Artigo

\title{
Educação Capitalista: \\ um produto rentável na sociedade contemporânea
}

\author{
Capitalist Education: \\ a profitable product in contemporary society \\ La Educación Xapitalista: \\ un producto rentable en la sociedad contemporánea
}

\begin{abstract}
L'Éducation Capitaliste:un produit rentable dans la société contemporaine
\end{abstract}

Allan Felippe Rodrigues Caetano ${ }^{1}$, Erick Herzog de Moraes $^{2}$ e Thamires Batello Freire ${ }^{3}$

\footnotetext{
${ }^{1}$ Graduado em Letras-Português e mestrando no Programa de Pós-Graduação em Neurociências e Comportamento no Instituto de Psicologia da Universidade de São Paulo, SP, Brasil.

E-mail: allan.caetano@usp.br

${ }^{2}$ Graduado em Psicologia e mestre em Psicologia Social pelo Instituto de Psicologia da Universidade de São Paulo, São Paulo, SP, Brasil. E-mail: erick.herzog@gmail.com

${ }^{3}$ Graduada em Farmácia pela Universidade São Judas Tadeu, SP, Brasil. Mestre em Ciências pela Universidade de São Paulo, SP, Brasil. Doutoranda no Programa de Pós-Graduação em Fármaco e Medicamentos na Área Cosmética pela Universidade de São Paulo, SP, Brasil. 
Resumo

Abstract
0 presente artigo tem como objetivo pensar a educação superior do estado de São Paulo diante do influente sistema capitalista. 0 modo como ele vem modelando práticas educativas no ensino superior é uma questão crítica devido a "coisificação" do ser em prol da manutenção dos ideais do capitalismo. 0 ponto de partida para tal reflexão inicia-se sob os pilares da educação grega, perpassando pela modernização da educação ocidental durante a revolução industrial que por fim, culmina em questões atuais sobre a comercialização do ensino superior. Para fundamentar algumas indagações contemporâneas, serão utilizadas como referencial teórico dados disponibilizados pelo Instituto Nacional de Ensino e Pesquisa INEP, referente ao número de cursos de graduação presencial no estado de São Paulo, assim como, a quantidade de matrículas efetuadas por alunos do sexo masculino e feminino, além da quantidade de concluintes dentre os mesmos durante o período de 1991 a 2015. A conclusão substancial desse exercício reflexivo evidencia que desde osprimórdios da educação grega, o sistema educacional, apesar de apresentar uma proposta humanística e integral, era acessível somente aos nobres. Durante a revolução industrial a educação passou a ser oferecida as grandes massas com o propósito de formar mão de obra mercadológica, da qual ainda observamos uma forte tendência segundo os modelos atuais de educação comercial. Propomos assim, a importância de retomar valores éticos exclusivamente humanos, como o respeito ao todo e a identidade dos indivíduos, além da possibilidade de oferecer uma formação justa que não segregue ou subtraia as potencialidades dos alunos.

Palavras-Chave: Educação Superior; Capitalismo, Educação Grega; Modernização da Educação; Comercialização da Educação.

The objective of this article is to think about the higher education of the state of São Paulo considering the influence of capitalism system. The way this sytem has been modeling educational practices in this context is a critical issue due to the process of "quantification" of the being in favor of maintaining the ideals of capitalism itself. The starting point of such reflexion underlies in the pilars of Greek education, passing through the modernization of Western education during the industrial revolution that culminates in modern questions about the commercialization of higher education. To support contemporary issues, it was used the theoretical reference data from the National Institute of Education and Research - INEP, referring to the number of presential graduation courses of the state of São Paulo, just as the quantity of enrollment made by male and female students and the number of graduated students between 1991 and 2015. The substantial conclusion of this reflexive exercise shows that from the earliest days of Greek education, the educational system, although presenting a humanistic and integral proposal, was accessible only to the nobles. During the industrial revolution, the education came to be offered to the masses, but with 
the goal of forming a labor force to the market. This is still a strong trend observed in the current models of commercial education. We propose, therefore, the importance of retaking exclusively human ethical values, such as respect for the society and the identity of individuals, as well as the possibility of offering a fair formation that does not segregate or subtract the potentialities of the students.

Keyword: Higher Education; Capitalism; Greek Education; Modernization ofEducation; Commercialization of Education.

Resumen

El presente artículo tiene como objetivo pensar "la educación superior del estado de São Paulo ante el influyente sistema capitalista". La forma en que el mismo viene modelando prácticas educativas en la enseñanza superior es una cuestión crítica debido a la "cosificación" del ser em del mantenimiento de los ideales del capitalismo. El punto de partida para tal reflexión se inicia bajo los pilares de la educación griega, pasando por la modernización de la educación occidental durante la revolución industrial que finalmente, culmina en cuestiones actuales sobre la comercialización de la enseñanza superior. Para fundamentar indagaciones contemporáneas, se utilizará como referencial teórico datos disponibles por el Instituto Nacional de Enseñanza e Investigación - INEP, referente al número de cursos de graduación presencial en el estado de São Paulo, así como la cantidad de matrículas efectuadas por alumnos del sexo masculino y femenino, además de la cantidad de concluyentes entre los mismos durante el período de 1991 a 2015. La conclusión sustancial de ese ejercicio reflexivo evidencia que desde los primordios de la educación griega, el sistema educativo a pesar de presentar una propuesta humanística e integral, era accesible sólo a los nobles. Durante la revolución industrial, la misma pasó a ser ofrecida las grandes masas, pero con el propósito de formar mano de obra mercadológica, de la cual aún observamos una fuerte tendencia según los modelos actuales de educación comercial. Proponemos así, la importancia de retomar valores éticos exclusivamente humanos, como el respeto al todo y la identidad de los individuos, además de la posibilidad de ofrecer una formación justa que no segregue o reste el potencial de los alumnos.

Palabras Clave: Educación Superior; Capitalismo; Educación Griega; Modernización de la Educación; Comercialización de la Educación .

Resumé

Le présent article a pour but de réfléchir à l'enseignement supérieur dans l'État de São Paulo face à l'influence du système capitaliste. La façon dont il a façonné les pratiques éducatives dans l'enseignement supérieur est une question critique en raison de l'"objectivation" de l'être en faveur du maintien des idéauxdu capitalisme. Le point de départ d'une telle réflexion 
commence sous les piliers de l'éducation grecque, en passant par la modernisation de l'éducation occidentale pendant la révolution industrielle qui, finalement, culmine dans les questions actuelles sur la commercialisation de l'enseignement supérieur. Pour répondre à certaines questions contemporaines, les données mises à disposition par l'Institut national de l'éducation et de la recherche - INEP seront utilisées comme référence théorique, en se référant au nombre de cours de premier cycle en classe dans l'État de São Paulo, ainsi qu'au nombre d'inscriptions d'étudiants et d'étudiantes, en plus du nombre de personnes ayant terminé ces cours entre 1991 et 2015. La conclusion substantielle de cet exercice de réflexion démontre que depuis le début de l'éducation grecque, le système éducatif, bien que présentant une proposition humaniste et intégrale, n'était accessible qu'aux nobles. Pendant la révolution industrielle, l'éducation a commencé à être offerte aux grandes masses dans le but de former une main-d'œuvre mercantile, dont on observe encore une forte tendance selon les modèles actuels d'éducation commerciale. Ainsi, nous proposons l'importance de reprendre des valeurs éthiques exclusivement humaines, telles que le respect des l'ensemble et de l'identité des individus, en plus de la possibilité d'offrir une éducation équitable qui ne ségrège pas et ne soustrait pas les potentialités des étudiants.

Mots-Clés: Enseignement Supérieur ; Capitalisme; Éducation Grecque; Modernisation de l'Éducation ; Commercialisation de l'Éducation. 
Ao pensarmos no atual modus operandi da educação superior do estado de São Paulo em comparação aos mecanismos que delineiam o sistema capitalista, podemos inferir que a formação acadêmica está intimamente relacionada aos interesses do sistema econômico. Apesar desta influência estar bem consolidada, vale mencionar que os pilares da educação ocidental foram embasados nos valores pedagógicos do período clássico grego, ou seja, a educação grega tinha como objetivo promover uma formação integral que pudesse educar tanto o corpo quanto a mente, perpassando assim pelos interesses econômicos da época, mas não se limitando ao mesmo. Afinal, como o sistema educacional superior se transformou em um processo de retroalimentação econômica, política, tecnológica e ideológica? Um dos momentos que marcaram a lógica da formação superior ocorreu durante a revolução industrial que impulsionou os valores idealizados pelo capitalismo. Neste período, a educação em massa possibilitou alienar os sujeitos de tal modo que não conseguissem elaborar uma visão crítica sobre os intuitos educacionais da época. Neste sentido, as forças econômicas usufruíram do sistema educacional como um meio de valorizar a formação técnica em prol do lucro, ou seja, a formação intelectual, moral, crítica e ética dos sujeitos foram excluídas do plano de educação tanto básico quanto superior.

Por outro lado, a formação educacional para os gregos tinha como intuito o desenvolvimento integral do sujeito, isto é, o amadurecimento de habilidades físicas e corporais que alinhadas ao trabalho intelectual proporcionaria a formação de indivíduos capacitados para usufruir de suas potencialidades internas através do ambiente externo. Tal formação era representada comumente pelo conceito de paidéia, cujo sentido pode ser compreendido como um processo consciente de ação educadora, da qual permite ao indivíduo desenvolver todo seu potencial humano. Aliás, este florescimento físico e intelectual transcendia a individualidade dos pupilos, já que eram orientados a cultivar e compartilhar suas virtudes frente a vida pública. Vale mencionar que o desenvolvimento intelectual, estético e artístico era viabilizado através da transmissão teórica e prática que advinham da figura do poeta como sendo o educador do seu povo. Além disso, a educação corporal complementava as perspectivas de vida do cidadão grego que poderia exercer funções técnicas e objetivas sem perder ou esquecer suas qualidades intelectuais ou simbólicas.

Avançando historicamente até o século XVIII, é notório que as mudanças ideológicas e econômicas ocorridas durante a revolução industrial repercutiram sobre a função da educação tanto para a sociedade quanto para o indivíduo, que afinal passou a receber uma formação educacional voltada para o mercado de trabalho. Aliás, assim como a estratificação social tornou-se cada vez mais demarcada, o acesso à escola e ao trabalho também foi delineado pelos poderes socioeconômicos. Enquanto os burgueses tinham acesso a ambientes de educação exclusivamente intelectual e artístico, os plebeus recebiam apenas uma formação que se consolidava juntamente ao trabalho braçal. Neste contexto, a relação trabalho-educação acabou sendo modelada pelas imposições do sistema capitalista, que por ser estruturada no ideal de sociedade de consumo, colaborou profundamente com o processo de "coisificação" do ser, que foi alavancada por uma educação tecnicista ao visar formar o cidadão apenas para servir como mão de obra para o mercado. 
O papel da educação ao longo da história vem sofrendo inúmeras mudanças de acordo com forças ideológicas, políticas e interesses econômicos de cada grupo ou nação em uma determinada época. É notório a importância de um sistema educativo que seja capaz de promover a formação dos indivíduos para a vida. No entanto, é possível observar que a formação dos sujeitos para o mercado de trabalho se tornou o principal objetivo das instituições de ensino superior tanto pública quanto privada, submetendo assim os estudantes a reproduzirem papeis sociais que na grande maioria das vezes são incongruentes com suas inclinações pessoais.

Frequentemente é possível encontrar indivíduos no mercado de trabalho que estão insatisfeitos com sua vida profissional, mas que assim o fazem devido a pressões socioeconômicas. Esta conjectura promove o adoecimento dos trabalhadores que ao longo do tempo são tidos como inválidos ao serem descartados pelo mercado de trabalho. Este ciclo de oferta e procura motivado pelo desgaste físico, emocional e mental, além da furiosa concorrêncialocal e global, acaba sendo nutrido pelas instituições de ensino superior que ao negligenciar umaformação multidisciplinar colaboram com este círculo vicioso.

Aliás, a falta de uma formação integral acentua a despreparação dos sujeitos para lidar com a diversidade cultural, religiosa, sexual e econômica que permeia a sociedade, colaborando assim para um engessamento intelectual que favorece a manutenção do sistema de reciclagem de mão de obra humana (Silva, 2007). Neste sentido, é importante ressaltar o papel de uma formação crítica que possa instrumentalizar os alunos para questionar os mecanismos institucionais que fomentam a padronização comportamental de indivíduos que se tornarão mera peças do sistema capitalista.

Tendo em vista as reflexões iniciais, este artigo objetiva refletir sobre a educação superior no estado de São Paulo perante o sistema capitalista. 0 intuito é promover uma análise sobre o estado atual da educação paulista em paralelo aos mecanismos do sistema econômico que estão minando as potencialidades humanas. Neste sentido, almeja-se promover uma reflexão crítica que possa contribuir para a elaboração de futuras diretrizes sobre o papel da universidade perante os desafios sociais que emergem das conjecturas econômicas. Para isso, serão utilizados dados coletados do Instituto Nacional de Estudos e Pesquisas Educacionais Anísio Teixeira (INEP), que vão embasar estatisticamente algumas questões sobre a educação superior e o mercado de trabalho. Em suma, os dados poderão fornecer um panorama sobre como a educação superior vem sendo manipulada pelos interesses do sistema capitalista, além de fomentar possíveis estratégias a serem aplicadas para a formação de uma consciência crítica sobre o verdadeiro papel da educação.

Tomando a Grécia como berço da sociedade ocidental, observamos que alguns conceitos desta civilização ainda ecoam na contemporaneidade. Como por exemplo, o conceito de paidéia que para os gregos significava uma formação humana baseada no espírito e na vida política, da qual norteava a formação do indivíduo como cidadão. No entanto, desde os primórdios da Grécia antiga o acesso à educação foi construído sob ideais excludentes dos quais favoreciam principalmente a nobreza e alguns militares da época que dispunham de recursos, tempo e renome para uma formação integral mais elaborada, enquanto que trabalhadores ou escravos eram limitados à ofícios braçais, dos quais recebiam pouca ou nenhuma instrução. 
A palavra paidéia também pode ser traduzida como "para meninos", o que denota uma clarasegregação de gênero. Uma vez que os cidadãos eram segregados entre proprietários de terra e escravos, o resultado era uma forte distinção entre a qualidade da educação oferecida para ambas as classes (Salviani, 2007). Enquanto a formação intelectual e artística era reservada a elite da época, o trabalho e a transformação da natureza eram tarefas para os menos abastados (Jaeger, 2001). Na idade média este contraste se acentuou, porém foi com o advento do capitalismo durante a revolução industrial que o trabalho se tornou protagonista da formação humana. No momento em que a elite dispunha de acesso a filosofia, matemática, música, política, arte e cultura durante a revolução industrial, a classe trabalhadora se aglomerava em grandes cidades onde desempenhavam funções fabris, basicamente mecânicas e exaustivas resultante da implementação de um tipo de linha de produção conhecida como fordismo (Tonet, 2012). Deste modo, a educação direcionada a estes trabalhadores adotou uma abordagem ainda mais simplista, ou seja, a exploração do homem no âmbito trabalho-capital, o que gerou diferenças abismais entre os direitos e deveres destes trabalhadores em relação as regalias e oportunidades acessíveis somente aos burgueses.

Tendo em vista as conjecturas históricas e sociais que fomentaram os modelos de ensino durante os séculos XVIII e XIX, alguns autores passaram a questionar o papel da educação, bem como das instituições que se encarregam de pratica-la. Entre os autores que refletiram criticamente sobre a função do sistema educacional estão Durkheim, Deleuze, Mészáros, Adorno e Foucault, além da importante corrente epistêmica pautada nos teóricos da Tróica (Vygotsky, Lúria e Leontiev), a qual investigava a função da educação em detrimento da sua diferenciação em relação ao aprendizado, à produção de conhecimento, ao papel da instituição que a centraliza (escola e suas dinâmicas) e a sociedade; bem como sua função social. Sendo assim, temos que por um lado o sujeito é formado a partir da educação, enquanto por outro, a sociedade tem seus mecanismos de controle, exclusão e inclusão, que acaba utilizando a educação como forma de reprodução e manutenção de seus interesses. Nesta perspectiva, a educação tem uma dupla importância para a discussão que se segue: a de problema central, e a de possibilidade de solução.

O sociólogo francês Émile Durkheim, no texto "Educação e Sociologia", apresenta argumentos que fundamentam uma visão dualista entre sujeito e sociedade: o sujeito que não vive num meio social, que não vivencia uma experiência de grupo, não é propriamente "humano", mas um "animal", que não concebe as normas e os laços sociais (Durkheim, 2013). Daí a necessidade da própria sociedade em educar os sujeitos, a fim de que estes estejam aptos a viver com outros. 0 autor é bastante direto no que diz respeito à função da educação: constituir o ser social no sujeito. Esta visão torna a educação central: por meio dela, os sujeitos se constituem socialmente, tornando possível a própria manutenção do meio social. Sua existência não seria meramente "sensata", ou "aconselhável", mas fundamental e obrigatória para a existência da sociedade, e para sua mudança (Durkheim, 2013). Outros autores, posteriores a Durkheim, analisam a educação de outra maneira. Entre eles particularmente Mészáros (2007), Adorno (1995), Foucault (2003) e Deleuze (1996) - há um movimento de não focar a educação exatamente como processo de constituição de um ser social, mas como um processo de constituição de um certo tipo de sujeito. Esta seria uma 
análise que leva mais em conta o contexto no qual a educação atua, quer dizer, pensa a educação sem ignorar as relações que esta tem junto a estrutura da sociedade na qual a prática educacional é incorporada (Oliveira, 2006).

Adorno, ao analisar a questão educacional, se pergunta para onde ela deveria conduzir. Seu fim ideal seria formar sujeitos autônomos, emancipados, os verdadeiros sujeitos de uma democracia, pois, segundo o autor, só existe democracia quando os sujeitos são emancipados, quando apresentam uma "consciência verdadeira" (Adorno, 1995). Todavia, até que ponto um sujeito completamente emancipado, "verdadeiramente consciente" estaria livre das relações de poder político, educacional, econômico, que a sociedade nos insere? Talvez seja sensato perceber a relatividade do conceito de "liberdade" com o qual estamos lidando. Doravante, faz- se necessário esclarecer que liberdade é um conceito absoluto para o autor. Assim, não é uma possibilidade exercê-la em sua plenitude na medida que os estratagemas que organizam as relações sociais no sistema capitalista são, em seus âmagos, cerceadores do desenvolvimento de plena consciência de exercício verdadeiro de liberdade. 0 esclarecimento aparece, dessa forma, como caminho para liberdade, na medida em que se situa como negação da ordem vigente. Ainda, esclarecimento e liberdade aparecem como potências para uma nova ordem social que seja justa, igualitária e digna. 0 que estes autores evidenciam é o uso que a sociedade faz da educação: esta acaba sendo instrumento de transmissão de formas de pensar e viver já pré- estabelecidas. Foucault diz, em suas palavras, que a escola não exclui, mas fixa as crianças a um aparelho de transmissão do saber (Foucault, 2003). Aí temos a noção de que a educação pode ser usada não para formar sujeitos autônomos, mas, ao contrário, sujeitos que simplesmente reproduzam a ideologia e a mentalidade dominante. O que acontece no sistema capitalista contemporâneo, é que qualquer instrumento de libertação, acaba sendo incorporado ao próprio sistema como um novo instrumento de normatização (Adorno, 1995). Assim, Adorno e outros autores pensaram a educação como uma forma de resistência a esta padronização. Se a educaçãoatual está indo no sentido oposto à conscientização e à autonomia, a "verdadeira educação" deve ser uma forma de resistir à dominação dos indivíduos.

Na obra "A Verdade e as Formas Jurídicas", Foucault vê a questão de modo parecido, no sentido de também indicar que a instituição educacional, de modo geral, teve seu papel distorcido, reduzido a um instrumento de manutenção do que ele chama de "sociedade disciplinar". Esta é a sociedade na qual reina o panoptismo, sendo esta uma forma de poder que exerce sobre os indivíduos uma vigilância contínua, de modo a controlar e corrigir (no sentido de formar e transformar os homens em função de certas normas). 0 triângulo básico do panoptismo consiste na vigilância, controle e correção (Foucault, 2003).

Na mesma obra, Foucault diz que o panoptismo vai totalmente contra as premissas teóricas do direito penal, formuladas por Beccaria, Bentham e outros teóricos do direito, no século XVIII. Estes, no contexto revolucionário europeu, instituíram uma reorganização do sistema judiciário e penal. Ela se funda num legalismo estrito, quer dizer, o julgamento e a punição são intimamente ligados a uma lei explícita. 0 crime então seria uma infração dessa lei penal explícita, que no fundo, causa dano à sociedade. Por isso, a lei penal teria a função de reparar ou prevenir o dano causado pela infração. Já o panoptismo não leva em consideração essa reorganização do sistema jurídico penal. Os instrumentos de penalidade das "sociedades 
disciplinares" não são ligados de fato a uma lei explícita, pois são utilizados considerando as possibilidades, as virtualidades, a periculosidade dos homens, ou seja, aquilo que não foi efetivamente feito, mas pode ser.

Diversas instituições segundo o autor, exemplificaram de modo extremo o panoptismo no século XIX. A maioria existe até hoje em uma forma mais branda. Algumas têm caráter pedagógico (escolas, orfanatos, centros de formação), outros correcionais (prisões, casas de recuperação, casas de correção) e outras correcionais e terapêuticas (hospital, hospital psiquiátrico, asilos). Elas são chamadas "instituições de reclusão", ou "instituições de sequestro". Esse nome vem da ação dessas instituições. 0 que ocorre no interior delas é uma "inclusão por exclusão". Contrariamente à prisão do século XVIII na França, mediada pelas lettres-de-cachet, pela qual excluía-se aqueles sujeitos com conduta marginalizada. As instituições de reclusão têm o objetivo, não de excluir, mas de fixar indivíduos em um aparelho de normalização, correção, produção ou de transmissão de saber, para incluir e normalizar. Essa fixação a qualquer um desses aparelhos, pela lógica do autor, consiste em reclusão, em sequestro. Daí o nome Pensando dessa maneira, o hospital psiquiátrico e a prisão não excluem, mas fixam os homens a um aparelho de normalização, correção. A fábrica não exclui, mas fixa os operários a um aparelho de produção. Aliás, a escola não exclui, mas fixa as crianças a um aparelho de transmissão de saber. Estamos aqui falando, portanto, de um fenômeno de exclusão que não retira o sujeito dos aparelhos sociais, outrossim de instrumentos que justamente fazem a manutenção do status quo. Nessa forma de organização, a instituição educacional funciona como parelho ideológico em que se perpetua o modo como se organizam as relações, incorporando e reproduzindo ideologias dominantes. Aqui os pontos de vista dos diferentes autores, sobretudo Adorno e Foucault (1995; 2003), convergem: leva-se em conta a possibilidade da instituição educacional ser instrumento de manutenção da sociedade que a incorpora, reproduzindo ideologias dominantes, modos de pensar e viver pré-programados que facilitam a gerência do status quo.

Todas as "instituições de reclusão" expostas por Foucault nada mais são do que instrumentos que visam, com a maior eficácia possível (com um poder polivalente, na medida em que todas apresentam poder jurídico, político, econômico e epistemológico) tornar o tempo dos homens tempo de trabalho, transformar o corpo dos homens em força de trabalho. Nesse contexto, escolas e centros de formação, de alguma maneira contribuem para um objetivo enraizado na "sociedade disciplinar", seja nos pequenos detalhes como a educação corporal, higiênica, ou na própria proposta pedagógica das escolas. A partir dessas ideias, podemos observar claramente na educação uma tendência a preparar os alunos a um mundo do trabalho, competitivo e especializado. É importante ressaltar, todavia, que a escola aparece para Adorno (1985) como instituição de dupla função. Suscintamente, o autor nos leva ao entendimento de que a educação caminha com o objetivo de promover a adaptação e a integração na sociedade, mas que esse não é seu único exercício. A educação, em sua forma mista e rica, deve também promover resistência.

Ao retomar Foucault, Gilles Deleuze coloca ênfase especial no conceito de sociedades disciplinares, mas não isoladamente - ele as coloca como sucessoras das sociedades de soberania, e precursoras do que se presencia atualmente: as sociedades de controle (Deleuze, 1996). Conclui-se, pois, o rumo que Foucault teorizou ao colocar as sociedades disciplinares 
como temporárias, transacionando a outra forma de submissão - diferente, mas tão intensa quanto as que sucedeu. Não se deve colocar este novo regime como melhor ou pior, porque há novas liberdades que antes não existiam, mas isto também vale para o contrário. Enquanto as sociedades disciplinares contavam com a massificação e individualização possibilitando vigília constante e moldando a individualidade dos componentes do grupo, respectivamente, as sociedades de controle utilizam senhas - cifras - para substituir a palavra de ordem e controlar o acesso do indivíduo. Ocorrendo assim, uma abstração do indivíduo, que Deleuze coloca como transformado em um ser "dividual", divisível, enquanto as massas passam a serem tratadas como amostras, dados, "bancos".

Com as sociedades de controle já tendo o indivíduo enquanto ser industrial sob controle, devido ao regime das sociedades disciplinares, ocorre uma transição do objeto de lucro. Com o processo de produção não sendo mais uma preocupação, o foco passa da produção para o produto em si: surge a indústria de serviços; o conceito de ações; e a empresa substitui a fábrica: "O controle é de curto prazo e de rotação rápida, mas também contínuo e ilimitado, ao passo que a disciplina era de longa duração, infinita e descontínua. 0 homem não é mais o homem confinado, mas o homem endividado" (Deleuze, 1996, p. 224). Em suma, ainda que todos os autores tenham uma visão criticamente contundente da educação como instrumento de controle da sociedade sob o sujeito, nenhum deles aponta uma solução pela simples exclusão da educação.

A psicologia sócio-histórica pode ser tomada como uma forte representante dos inúmeros esforços para a formulação de explicações acerca do psiquismo sem desgarrá-lo das condições objetivas que sustentam sua formação, encontrando no materialismo histórico dialético o aporte filosófico de suas proposições. Os postulados da epistemologia marxista se concretizam nela tanto no plano teórico, como estofo de seus princípios e concepções científicas gerais, quanto no plano metodológico, isto é, nas articulações entre os fundamentos teóricos e os dados empíricos de investigação. Neste sentido, o estudo dos fundamentos epistemológicos da psicologia sócio- histórica representa um primeiro passo para a compreensão de seus postulados.

Para Saviani (1991), a educação (enquanto natureza) parte de um processo de trabalho, ou melhor, constitui-se em um. Conforme ele mesmo lembra, o homem é um ser que constantemente produz para depois (re)produzir, sendo este produto dado pelo trabalho. É a partir deste movimento histórico que os humanos fazem cultura, e a fazem coletivamente. Daí porque, se diz que ao homem cabe adaptar a natureza e transformá-la.

Nesse sentido, o autor pensa a educação também como uma atividade produtiva, dentro das culturas que os homens coletivizam. Para ele, tudo passa pela produção da existência humana, pressuposto que coloca o homem num processo permanente de trabalho para garantia da sobrevivência. Dentro deste ato de produzir, Saviani coloca as expressões trabalho material e trabalho não-material, para se referir à questão dos bens. No intento de justificar a primeira, o autor lembra dos bens materiais necessários à subsistência material de cada indivíduo; em relação à segunda, fala dos saberes e/ou produtos subjetivos, ou seja, as ideias, artes, conceitos, valores, símbolos, hábitos, habilidades etc. Assim, Saviani pressupõe o ato de educar como um ato produtivo e consumível ao mesmo tempo. No caso do ensino em 
sala de aula, por exemplo, afirma ser o professor um produtor (neste caso do conhecimento; atividade não-material), aquele que está produzindo para o consumo dos educandos.

Quanto ao que concerne aos outros modelos de escola - que não se orientam pela pedagogia histórico-crítica - temos, inicialmente, como objeto de crítica a escola tradicional, onde os conhecimentos e valores sociais são repassados ao aluno muitas vezes como verdade absoluta e inquestionável. Não distante disso, os métodos se baseiam na exposição verbal da matéria, sendo feitas pelo professor, - modelo magistrocêntrico -, do qual se dava ênfase nos exercícios, na repetição de conceitos ou fórmulas de memorização, disciplinando a mente a formar hábitos. 0 que predominava era a autoridade do professor, não havendo qualquer tipo de aproximação entre o mesmo e o aluno no decorrer das aulas. Lembrando assim, a ideia de educação bancaria proposta por Paulo Freire.

Ao escolanovismo cabe a consideração de que o processo de humanização não ocorra isoladamente. Para a psicologia sócio histórica e para a pedagogia histórico crítica, a personalidade e o psiquismo não se desenvolvem isoladamente e sua mediação durante a apropriação dos signos historicamente acumulados é um requisito básico para o "sucesso" nesseprocesso.

A crítica reprodutivista, expressa na teoria da escola como aparelho ideológico do Estado e na teoria de produção da escola dualista, evidencia o sucateamento da educação, que simplesmente corrobora com a mercantização da mesma. É notório que as instituições não promoventes de uma educação que vise a equidade entre os indivíduos e a abolição dos conflitos de classes, são fomentadas pelo ideal burguês. Tendo na estrutura do Estado um governo que caminhe suas políticas públicas conjuntamente ao ideal burguês, todos os modelos supracitados (salvo a pedagogia histórico-crítica), não são verdadeiras teorias que se engajem na emancipação do homem.

Em vista a tudo isso, fica a consideração de que a escola se tornou uma instituição formadora de trabalhadores que beneficiam os retentores dos meios de produção, deixando livremente que os conteúdos dados, bem como as dinâmicas de interações, sejam orientados pelo egoísmo, competitividade e qualificação por desempenho (meritocracia). Esse é o máximo ponto de encontro entre a educação e a ideologia neoliberal, que intenta a produção taylorista, acelerada de operários multifuncionais, disciplinados e facilmente recicláveis, isto é, corroboradora de uma dinâmica formatadora de um trabalhador adequado ao modelo de produção alienadora e explorativa.

A partir do ano de 1997, com a abertura do mercado econômico para Instituições de Ensino Superior (IES) privadas, com os Decretos número 2207 e 2306, seguida pela abertura de capital e Oferta pública inicial (OPI) na Bolsa de Valores paulista das quatro primeiras empresas educacionais (Kroton, Estácio, Anhanguera e SEB), esta dinâmica muda: o principal objetivo é visar o maior lucro possível. 0 motivo central para que esta mudança ocorresse é que, a educação se tornou um negócio muito rentável: até a edição das Portarias 21 e 23 do Fies, de 29/12/2014, o setor educacional do mercado de ações foi o mais lucrativo dentre os 16 setores da economia presente na Bovespa.

Deste modo, a partir da implementação dos Decretos supracitados, as empresas responsáveis por instituições privadas implementaram uma série de mudanças tendo em vista elevar seu lucro em detrimento da qualidade do ensino. Como exemplo, podemos citar a 
diminuição do custo por aluno, a expansão do número de matrículas disponíveis, a diminuição do período de conclusão de alguns cursos de graduação, a criação de modalidades como o Ensino a Distância (EAD), a ampliação de vagas de estudo no período noturno e por fim, o sucateamento do quadro de professores.

A modalidade EAD de educação, tem como principal característica o ambiente virtual como plataforma de ensino, o que proporciona a não necessidade da presença física tanto do aluno quanto do professor, pois todos os materiais disponíveis para as aulas são arquivados em vídeos, áudios, textos e outros recursos eletrônicos. Por meio da facilitação tecnológica esta modalidade cresceu muito entre instituições privadas principalmente por ser mais econômica, uma vez que não é necessário investir em espaços físicos ou laboratórios, além da redução do número de educadores. Outro motivo para a expansão dos cursos a distância, foi a flexibilização das regras para abertura de determinados cursos e o corte do orçamento das IES públicas realizado em 2005. Segundo Sguissardi (2015), entre os períodos de 2002 a 2012, houve um aumento de $1768 \%$ de matrículas em cursos a distância, sendo que no ano de 2012, 84\% dessas matrículas eram em instituições particulares.

Além disso, vale destacar a preferência por cursos no período noturno que vem crescendo fortemente devido à demanda de alunos que trabalham durante o dia, mas que acabam sendo lesados devido ao acúmulo de obrigações do sistema que mina suas energias limitando a formação do aluno e penosas tarefas desprazerosas. Segundo dados do mesmo estudo, a proporção de alunos que estudam no período noturno cresceu de $58 \%$ para $63 \%$, sendo que nas IES privadas, $73,2 \%$ estudam no período noturno.

Com relação a distribuição de matrículas por áreas do saber, em 2009, 89\% concentravam- se em áreas da Educação, Negócios, Direito e Ciências Sociais. Sendo que estes cursos acabam sendo mais baratos devido a não necessidade de uma infraestrutura especial, o que diminui o custo para as empresas.

Outro ponto relevante é a relação entre estas instituições e programas federais que custeiam a permanência de jovens no ensino superior particular. Como exemplo, citamos o Programa Universidade Para Todos (PROUNI) que beneficia estudantes carentes do ensino médio público com bolsas de estudos de até $100 \%$ para IES privadas, no entanto, muitas vezes o aluno acaba recebendo uma educação sucateada que o prepara de modo inadequado tanto intelectualmente como profissionalmente. Além disso, as instituições que aceitam alunos beneficiados com bolsas recebem uma série de isenções fiscais e dedução de impostos concedidos pela União, o que reforça um sistema educacional que visa o lucro em detrimento da qualidade do ensino (Sguissardi, 2015).

Uma das formas de garantir a adesão de mais alunos pelas IES privadas se refere, ao modo como algumas empresas educacionais utilizam o marketing sensacionalista a seu favor. 0 recurso da publicidade e propaganda sempre foi utilizada, porém em 2015, quando houve um corte no orçamento da Educação e no Fies, as campanhas publicitárias se intensificaram. Com a dificuldade dos alunos em conseguir um financiamento pelo Fies, as universidades particulares reduziram ainda mais as mensalidades, a carga horária dos cursos, o número de professores e ampliaram a educação a distância, sendo que, entre as estratégias citadas anteriormente na captação de novos alunos, se destaca o emprego do merchandising incisivo que faz uso de figuras públicas afim de fidelizar o público as qualidades atribuídas a algum 
ícone midiático. Como exemplo, podemos citar a propaganda que utiliza o slogan "Vem conversar que a gente faz dar certo", onde um apresentador de televisão conhecido nacionalmente tenta convencer o público de que existe uma real preocupação com sua formação educacional, da qual permitirá ao futuro aluno uma inserção imediata no mercado de trabalho. Neste contexto, podemos questionar como é possível garantir um ensino de qualidade com preços tão baixos, com ideologias tão pobres e com professores tão mal remunerados e formados. Vale destacar também, o afrouxamento constante das regras de regulamentação das EAD imposta pelo Ministério da Educação (MEC) que em 2017, possibilitou que IES passassem a oferecer cursos EAD mesmo sem possuir credenciamento de cursos presenciais, além de não tornar necessária a prévia aprovação do MEC para a abertura de polos EAD.

Outro cenário que contribui para a desfiguração da educação é a importância dada ao diploma no cenário nacional. Neste caso, ocorrem dois problemas principais: uma saturação no mercado de trabalho entre cargos que exigem uma formação de nível superior e casos onde ocorre a venda de diplomas para sujeitos que não possuem oportunidade ou tempo de realizar um curso superior. Por haver o pensamento de que o diploma equivale a um status superior e uma melhoria imediata na qualidade de vida, há uma distorção no valor dado a educação, uma vez que, há indivíduos que pagam para receber o "canudo" que comprove que os mesmos possuem um determinado conhecimento sem ao menos possui-lo.

Todos os pontos discutidos até agora, exemplificam de que maneira o aluno está sendo "coisificado" durante sua permanência na educação superior, seja por ser tratado apenas como mais um número para grandes empresas de educação superior privada, quanto por julgar necessário apenas a existência do diploma para avaliar seu valor como ser. Para mudar este cenário, o ensino superior deveria levar em conta “(...) frequência, sucesso acadêmico e conclusão dos cursos por parte dos alunos (...)" (Almeida, 2014, p. 90), além de considerar e valorizar experiências anteriores, quer pessoais, profissionais, ou que possibilite formar um quadro de inclusão multicultural.

Tendo em vista um panorama histórico e sociocultural do qual partimos da educação grega perpassando pelas mudanças durante o século XVIII a XXI, passamos agora a empregar dados estatísticos colhidos a partir do site do INEP para melhor embasar algumas reflexões acerca da educação superior no estado de São Paulo e sua relação com o sistema capitalista.

Ao observarmos a Figura 1, que mostra o número de cursos de graduação presenciais oferecidos em instituições públicas e particulares no estado de São Paulo, é possível notar uma tendência de progressão linear entre 1991 à 2015 referente a instituições públicas, possivelmente devido ao empobrecimento e ao descrédito da qual a mesma vem sendo fortemente enraizada. Em oposição a instituições públicas, vemos uma expressiva linearidade ascendente devido ao número de oferta de cursos oferecidos por instituições particulares, além dos planos de orçamento oferecido pelas mesmas. Além disso, o cenário estagnador de ofertas de vagas em instituições públicas estimulou a absorção da demanda pelas instituições privadas.

A partir dos anos 1990, a educação superior privada brasileira sofreu fortes impulsos e pressões políticas por parte do governo Fernando Collor de Mello que enfatizou a superioridade e eficiência do mercado de educação privado em absorver as demandas do setor. Isso ocorreu, a partir da necessidade de privatização da educação a fim de fortalecer o mercado lucrativo e diminuir a necessidade de fornecimento de educação de nível superior pelo estado. Durante a mesma década, o irrisório aumento do número de cursos de graduação em instituições públicas ocorreu dentre tantos fatores devido ao 
sucateamento das mesmas e aos fortes investimentos aplicados a instituições privadas. Neste contexto, os incentivos financeiros a instituições privadas acabaram por suprir as lacunas abertas pelo setor público referente a educação superior (Mancebo, 2006).

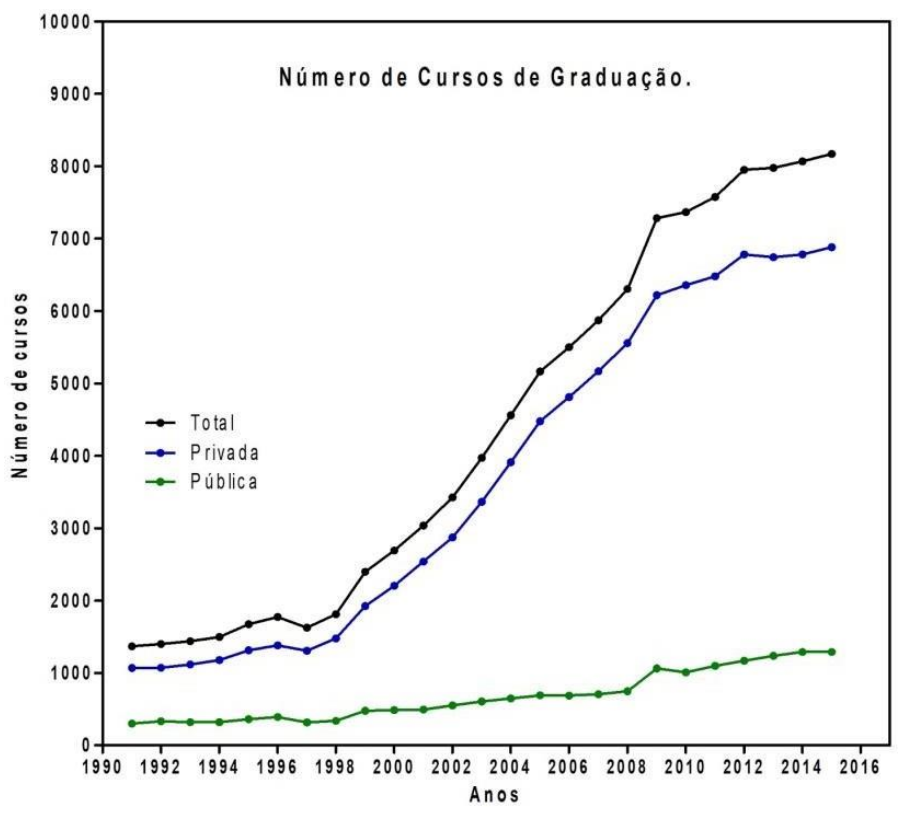

Figura 1. Número de cursos de graduação oferecidos no estado de São Paulo por instituições públicas e privadas dentro do período de 1991 a 2015. (Círculos cheios, cor preta) representam o total de cursos oferecidos no ano. (Círculos cheios, cor azul) representam a quantidade de cursos oferecidos por instituições privadas. (Círculos cheios, cor verde) demonstram a quantidade de cursos oferecidos por instituições públicas. Dados do INEP.

Na Figura 2, é notável a crescente quantidade de matrículas efetuadas em instituições particulares tanto pelo gênero feminino quanto masculino em comparação a inscrição em instituições públicas. 0 número de matrículas efetivadas pelo público feminino é superior em relação ao masculino, dado este que não corrobora com o observado nas instituições públicas, pois nestas a quantidade de homens e mulheres não apresentam grande distinção quantitativa. Um dos motivos pelo qual o nível educacional das mulheres vem aumentando nas últimas décadas, se deve ao fato que, a formação superior passou a ser requisito obrigatório para quem almeja acender a melhores cargos, além de uma competitividade com o público masculino que por questões histórico culturais vêm ocupando cargos de chefia, que agora está sendo conquistado pelas mulheres. A inserção da mulher no mercado de trabalho se deu a partir do final do século XVIII, onde um maior número de profissionais, sejam estes homens, mulheres ou crianças, fez com que a produção e acumulação do capital tornasse mais eficiente, pois o maior número de operários para cumprir a mão de obra, desvaloriza a força de trabalho anteriormenteexercida apenas pelo homem (Marx, 1989, p. 450). 


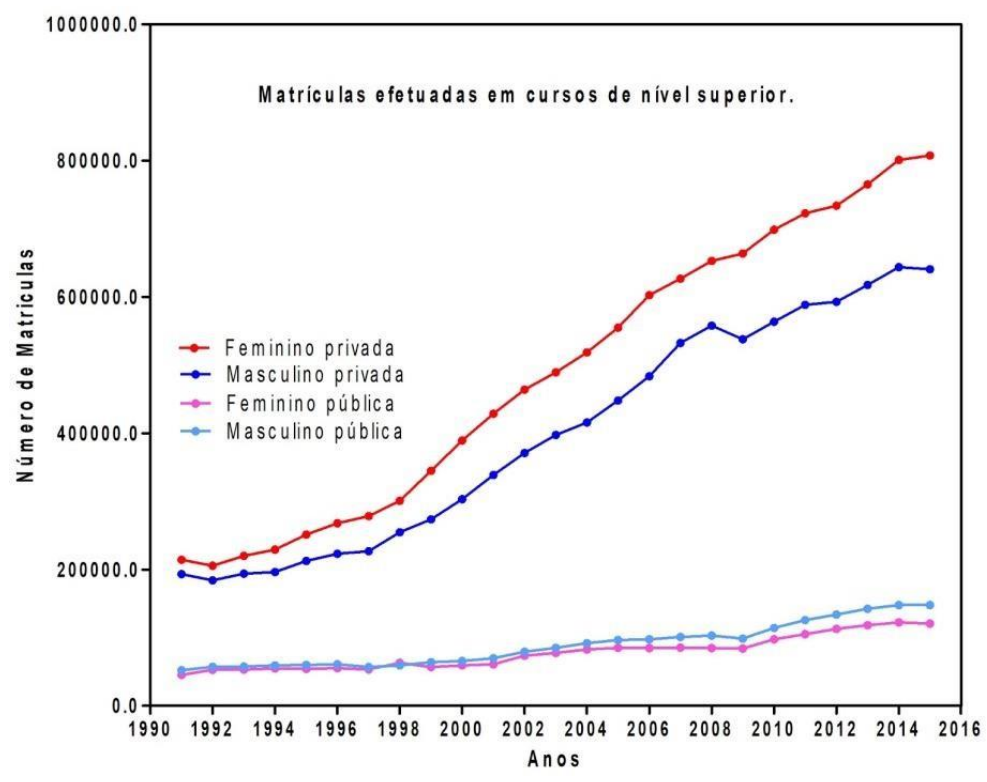

Figura 2. Número de matrículas em cursos de graduação efetuados no estado de São Paulo por instituições públicas e privadas dentro do período de 1991 a 2015, discriminados por gênero. (Círculos cheios, cor vermelha) representam o total de matrículasefetuadas por mulheres em instituições privadas nos cursos de nível superior a cada ano. (Círculos cheios, cor azul escuro) representam o total de matrículas efetuadas por homens em instituições privadas nos cursos de nível superior a cada ano. (Círculos cheios, cor rosa) representam o total de matrículas efetuadas por mulheres em instituições públicas nos cursos de nível superior a cada ano. (Círculos cheios, cor azul claro) representam o total de matrículas efetuadas por homens em instituições públicas nos cursos de nível superior a cada ano. Dados do INEP.

A terceira figura esboça o número de concluintes em cursos de nível superior pública e privada entre ambos os sexos. De acordo com INEP, os níveis de evasão giram em torno de $20 \%$ em centros de formação superior. Ademais, em universidades públicas como a Universidade de São Paulo o número gira em torno de 20,2\% corroborando assim com o porcentual nacional (USP jornal do campus). Dentre o público feminino e masculino de instituições privadas, o último revela uma maior defasagem, o que pode ser relacionado a uma maior dominância do mercado de trabalho pelas mulheres, além de uma mudança de concepção entre valores e o papel dos respectivos gêneros. Referente ao número de concluintes nos centros de formação públicos, se observa uma estabilidade quase equânime entre os dois sexos, muitas vezes devido aos imperativos do sistema que ceifa a possibilidade de uma formação contínua entre os mesmos. Dados estes que corroboram com Sguissardi (2015), que relata um aumento da procura pelo ensino particular devido a mercantilização do ensino no Brasil em meados de 2014. 


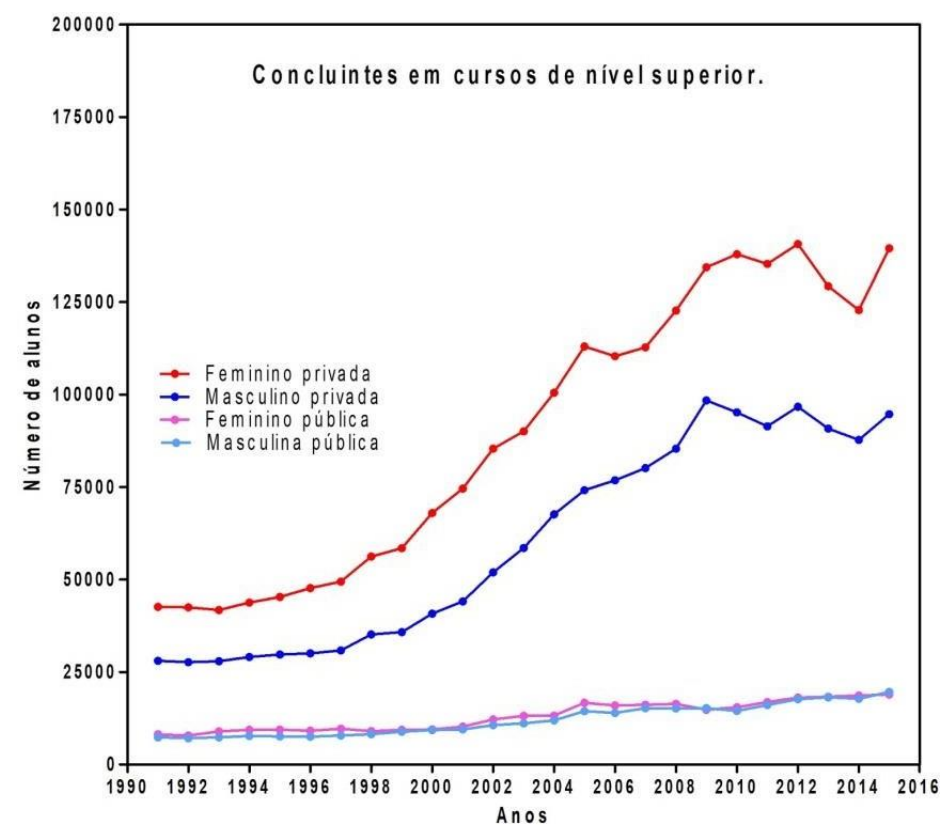

Figura 3. Número de concluintes em cursos de graduação no estado de São Paulo por instituições públicas e privadas dentro do período de 1991 a 2015, discriminados por gênero. (Círculos cheios, cor vermelha) representam o total de mulheres concluintes em cursos de graduação em instituições privadas a cada ano. (Círculos cheios, cor azul escuro) representam total de homens concluintes em cursos de graduação em instituições privadas a cada ano. (Círculos cheios, cor rosa) total de mulheres concluintes em cursos de graduação em instituições públicas a cada ano. (Círculos cheios, cor azul claro) representam o total de homens concluintes em cursosde graduação em instituições públicas a cada ano. Dados do INEP.

Não é uma tarefa fácil abranger mesmo que parcialmente o espectro de acontecimentos políticos, econômicos e sócio históricos que influenciaram o desenvolvimento institucional do ensino superior no estado de São Paulo. No entanto, o intuito deste artigo foi apresentar uma visão panorâmica que pode ajudar a refletir criticamente sobre a relação entre os interesses do sistema capitalista e a função do sistema educacional superior. Inicialmente partimos da concepção grega de educação que edificou os pilares do sistema educativo ocidental. Foi possível constatar que os problemas educacionais emergiram desde a Grécia antiga, na qual já apresentava uma estratificação socioeducativa entre aqueles que tinham acesso à educação integral e os que ficavam a margem desta. Em seguida, relatamos algumas mudanças ocorridas ao longo do século XVIII e XXI, que impactaram diretamente os projetos educacionais da época. Afinal, durante a revolução industrial, a relação entre escola e trabalho se estruturou em um mesmo pilar, do qual sustentava principalmente as demandas comerciais da época. Por fim, os dados recolhidos da fonte do INEP, possibilitaram vislumbrar como o sistema capitalista vem reorganizando as diretrizes acadêmicas perante as demandas socioeconômicas dos alunos. A partir deste roteiro foi possível constatar como o sistema capitalista vem cerceando as instituições superiores a um papel meramente reprodutivo. Em outras palavras, podemos inferir que o sucateamento do ensino superior vem ampliando a estratificação sociocultural, além das diversas formas de preconceito que acabam sendo normatizadas dentro dos moldes imperialistas sobre o ideal de vida bem-sucedida. Por fim, concluímos que a formação intelectualsuperior deve ser fundamentada principalmente no desenvolvimento do raciocínio crítico que pode ser construído através de uma formação multidisciplinar que favoreça o pleno desenvolvimento das capacidades objetivas e subjetivas de cada indivíduo que pertence a um grupo. 


\section{Referências Bibliográficas}

Adorno, Theodor W. (1995). Educação e Emancipação. Rio de Janeiro: Paz e Terra.

Almeida, Leandro., Marinho-Araujo, Claisy., Amaral, Alberto., \& Dias, Diana. (2012). Democratização do acesso e do sucesso no ensino superior: uma reflexão a partir das realidades de Portugal e do Brasil. Avaliação, 17(3), 899-920. Acessado em 19 de maio de 2019, de: https://doi.org/10.1590/S1414-40772012000300014

Deleuze, Gilles. (1996). Conversações (2a ed.). São Paulo: Editora: 34.

Durkheim, Émille. (2013). Educação e Sociologia. (Trad. Stephania Matousek). Petrópolis: Vozes.Foucault, Michel A. (2003). A verdade e as formas jurídicas. Rio de Janeiro: NAU.

Freire, Paulo. (1977). Ação cultural para a liberdade (2 $2^{\underline{a}}$ ed.), (1 $1^{\text {a }}$ edición: 1975). Rio de Janeiro: Paz e Terra.

Instituto Nacional de Estudos e Pesquisas Educacionais Anísio Teixeira. Sinopse estatística de educação superior 1991 a 2015. Brasília: Inep. Acessado em 10 setembro de 2019, de: http://portal.inep.gov.br/web/guest/sinopses-estatisticas-da-educacao-superior

Jaeger, Werner. (1995). Paidéia: A Formação do Homem Grego. (Trad. Artur M. Parreira). Martins Fontes, São Paulo.

Mancebo, Deise., Maues, Olgaíses., Chaves, Vera, \& Lúcia, Jacob. (2006). Crise e reforma do Estado e da Universidade Brasileira: implicações para o trabalho docente. Educação em revista, (28), 37-53. Acessado em 19 de maio de 2019, de: https://doi.org/10.1590/S010440602006000200004

Karl, Marx. (1989). O Capital. Crítica da economia política (13 a ed.). Rio de Janeiro: Bertrand Brasil. Vols. I e II.

Mészáros, István. (2007). A educação para além do capital. Theomai, (15), 107-130. Acessado em 10 de maio de 2019, de: http://revistatheomai.unq.edu.ar/numero15/artmeszaros 15.pdf

Oliveira, Dalila Andrade. (2006). Educação para além do capital. Educação \& Sociedade, $\begin{aligned} 27(97), 1373-1376 . & \text { Acessado em } 19 \text { de maio } \\ \text { de } & 2019, \text { de: }\end{aligned}$ https://www.scielo.br/pdf/es/v27n97/a16v2797.pdf

Platão. (2001). República. (Trad. Maria Helena da Rocha Pereira) (9 a ed.). Lisboa: Fundação Calouste Gulbbenkian.

Saviani, Dermeval. (1991). Pedagogia Histórico-Crítica, primeiras aproximações. Campinas, SP: Autores Associados.

Saviani, Dermeval. (2007). Trabalho e educação: fundamentos ontológicos e históricos. Revista Brasileira de educação, 12(34), 152-165. Acessado em 19 de maio de 2019, de: https://doi.org/10.1590/S1413-24782007000100012

Sguissardi, Valdemar. (2015). Educação Superior no Brasil. Democratização ou massificação mercantil? Educação \& Sociedade, 36(133), 867-889. Acessado em 19 de maio de 2019, de: http://dx.doi.org/10.1590/ES0101-73302015155688 
Silva, Alessandro Soares da. (2007). Direitos Humanos e Lugares Minoritários: um convite ao pensar sobre os processos de exclusão na escola. Em: Ministério da Educação. Programa Ética e Cidadania: construindo valores na escola e na sociedade. Acessado em 19 de maio de 2019, de: http://portal.mec.gov.br/seb/arquivos/pdf/Etica/11 soares.pdf

Silva, Katiane., \& Toledo Maria. (2013). A docência e seus desafios: um olhar crítico acerca da comercialização da educação. Revista Ciências Humanas, 1(6), 107-19.

Tonet, Ivo. (2012). Educação contra o capital. Educação e Formação Humana (2 a ed.). São Paulo: Instituto Lukács. Acessado em 19 de maio de 2019, de:

USP jornal do campus. Mais de 20\% dos alunos deixam a USP. Acessado em 5 outubro de 2019, de: $\quad$ http://www.jornaldocampus.usp.br/index.php/2016/10/basic-

2/\#: :text=Um\%20estudo\%20realizado\%20pela $\% 20 \mathrm{Pr} \%$ C3\%B3,para $\% 200 \% 20$ ensino $\% 2$

Recebido em 07/11/2018. 